\title{
Systemic endotoxin activity correlates with clot formation: an observational study in patients with early systemic inflammation and sepsis
}

\author{
Alexander Koch ${ }^{*}$, Michael Isaäc Meesters ${ }^{2}$, Bertram Scheller ${ }^{1}$, Christa Boer ${ }^{2}$ and Kai Zacharowski ${ }^{1}$
}

\begin{abstract}
Introduction: Inflammation and coagulation are closely linked, and both can be triggered by endotoxin. Thrombelastometry and impedance aggregometry are of diagnostic and predictive value in critically ill patients. In this observational study we investigated the correlation of endotoxin activity with thrombelasometric and aggregometric variables in patients with systemic inflammation.

Methods: Based on a daily screening on a tertiary academic surgical ICU, patients, as soon as they fulfilled two or more criteria for systemic inflammatory response syndrome (SIRS), were included. In whole blood we performed endotoxin activity (EA) assay, thrombelastometry $\left(\right.$ ROTEM $\left.^{\circledR}\right)$ and impendance aggregometry (Multiplate ${ }^{\circledR}$ ).

Results: In total, 49 patients were included with a broad spread of EA levels of (median (minimum to maximum)) 0.27 (0.01 to 0.72), allowing expedient correlative analysis. Clot formation time (CFT) (263 s (60 to 1,438 s)) and clotting time $(C T)(1,008 \mathrm{~s}(53$ to 1,481 s)) showed a significant negative correlation with EA level $(r=-0.38(P<$ $0.005)$ and $r=-0.29(P<0.05))$. Positive correlations were found for alpha-angle $\left(50^{\circ}\left(17\right.\right.$ to $\left.78^{\circ}\right), r=0.40(P<$ $0.005))$ and maximum clot firmness (MCF) $(55 \mathrm{~mm}(5 / 76), r=0.27(P<0.05))$. No significant correlations were found between Lysis Index at 60 minutes (LI60) and EA levels. There was no correlation between EA level and aggregometric values, or classical coagulation parameters.
\end{abstract}

Conclusions: In patients with systemic inflammation, increasing endotoxin concentrations correlate with increased clot formation.

\section{Introduction}

During systemic inflammation, endotoxin (lipopolysaccharide (LPS)), can originate from invading Gram-negative bacteria and/or translocation of endogenous Gramnegative wall fragments. Translocation of endotoxin appears in the context of gastrointestinal hypoperfusion and gut failure, a frequently observed pathophysiology on intensive care units [1]. Subsequently, LPS is released into sterile compartments of the organism and in turn is detected by pattern recognition receptors (PRRs), like toll-like receptor (TLR)4, resulting in initiation of inflammation and coagulation [2,3]. In critically ill patients, concentrations of endotoxins are elevated and

\footnotetext{
* Correspondence: alex.koch@usa.net

${ }^{1}$ Clinic of Anesthesiology, Intensive Care Medicine and Pain Therapy, University Hospital Frankfurt, Theodor-Stern-Kai 7, Frankfurt am Main 60590, Germany

Full list of author information is available at the end of the article
}

measurable with the endotoxin activity (EA) assay. EA levels correlate with Acute Physiology and Chronic Health Evaluation II (APACHE II), the presence of severe sepsis and mortality [4].

The cross-talk between inflammation and coagulation is a central player in the pathophysiology of systemic inflammation and sepsis [5,6]. In vitro and in vivo models demonstrate the potential of LPS to initiate clotting. Added to whole blood, LPS reduces clotting time (CT) as measured with (rotational) thrombelastometry (TEM) $[7,8]$. Compared to healthy controls, both postoperative patients and patients with sepsis demonstrate shorter CTs and clot formation times (CFTs) [9]. In septic patients, particularly CFT seems to correlate well with clinical condition and outcome [10].

Furthermore, systemic inflammation alters platelet function, and under certain conditions, sepsis can lead to activation and aggregation of platelets [11-13]. However, more

\section{() Biomed Central}


recent data demonstrate reduced platelet aggregation in patients with severe sepsis compared to postoperative patients [14]. The Multiplate ${ }^{\circledR}$ analyzer is a modern type of impedance aggregometer which is designed as a bedside tool (point of care) to assess platelet function [15].

The correlation between EA levels and thrombelastometric or aggregometric measurements during systemic inflammation has not been evaluated yet. The further understanding of the relationship of systemic inflammation and coagulation in patients might be of relevance for the introduction of new therapeutic approaches. For example, endotoxin neutralizing or eliminating concepts could also positively influence coagulatory dysregulations in these patients.

The primary outcome of this prospective observational study was the association of EA level and CFT in patients with early systemic inflammation. Secondary outcomes were the association of EA levels with further thrombelastometric and aggregometric measurements and the influence of infection (that is, sepsis).

\section{Materials and methods Patients}

This single center prospective observational study included adult patients with two or more systemic inflammatory response syndrome (SIRS) criteria on a 26-bed tertiary academic surgical ICU. The study was approved by the local ethical review committee (University Hospital Frankfurt, Germany) and carried out in compliance with the principles established in the Helsinki Declaration. Written informed consents were obtained from the patients or legal representatives for patients unable to consent. From April to July 2011, on a daily basis between $06: 30$ to $07: 30$ am, all patients were screened for SIRS criteria [16]. Patients fulfilling two or more of the following SIRS criteria were included: (a) core temperature of $>38^{\circ} \mathrm{C}$ or $<36^{\circ} \mathrm{C}$, (b) heart rate of $>90$ beats/minute, (c) respiratory rate of $>20$ breaths/minute or partial pressure of arterial carbon dioxide $\left(\mathrm{PaCO}_{2}\right)<32 \mathrm{mmHg}$ (all patients screened were breathing spontaneously), (d) total WBC absolute count $>12,000$ cells $/ \mathrm{mm}^{3}$ or $<4,000$ cells $/ \mathrm{mm}^{3}$. Sepsis was diagnosed when additionally, microbiological results revealed an organism grown in blood/sterile sites or infected tissue was detected clinically (for example, pneumonia).

Exclusion criteria: age $<18$ years, denial of informed consent, chronic liver disease, treatment with anticoagulants other than heparin or low molecular weight heparin (LMWH), history of coagulopathy or thrombophilia.

\section{Procedures}

Demographic variables, routine blood tests, including conventional clotting, clinical and microbiological data were collected. Blood samples were obtained between
08:00 a.m. and 12:00 p.m. (noon) on the day of inclusion. Inclusion bias was avoided by including patients before measurements were performed. Blood samples were drawn from an indwelling arterial line (flush setups were not heparinised) and consisted of one EDTA-, one citrate-tube and one heparinised tube, for EA, thrombelastometric, and aggregometric measurements, respectively. Measurements were performed within one hour. EA levels were determined by Endotoxin Activity Assay (EAA) (EAA ${ }^{\mathrm{TM}}$, Spectral Diagnostics Inc., Toronto, ON, Canada), according to the manufacturer's instruction. Rotational thromboelastometry measurements were performed according to the manufacturer's recommendations $\left(\right.$ ROTEM $^{\circledR}$, Tem International GmbH, München, Germany). A total of $300 \mu \mathrm{L}$ of citrated blood was pipetted into ROTEM ${ }^{\circledR}$ sample cups and heparinase (to exclude potential effects of heparin) and $\mathrm{CaCl}_{2}(20 \mu \mathrm{l}$ heparinase and $0.2 \mathrm{M} \mathrm{CaCl}_{2}$, NATEM-test) were added. The NATEM-test was chosen since no activators are added. In vitro experiments revealed that endotoxin initiated clotting activation cannot be measured sufficiently by thrombelastometry when performed with additional clotting activators [7]. Furthermore, the NATEM-test has been previously evaluated in patients with systemic inflammation $[9,10]$. Sample tubes were temperature controlled at $37^{\circ} \mathrm{C} . \mathrm{CT}, \mathrm{CFT}$, maximum clot firmness (MCF), alpha angle and 60-minute lyses index (LI60) were determined. Platelet function was investigated by impedance aggregometry using Multiplate $^{\circledR}$ (Verum Diagnostica GmbH, Munich, Germany) analysis according to the manufacturer's recommendations. A total of $300 \mu \mathrm{l}$ heparinised whole blood and 300 $\mu \mathrm{l}$ saline was pipetted into the test cells which were temperature controlled at $37^{\circ} \mathrm{C}$. Samples were activated with arachidonic acid (ASPI), adenosine diphosphate (ADP), or thrombin receptor activating peptide 6 (TRAP). Results are given as area under curves of arbitrary aggregation units (A.U.) over time.

\section{Statistical analysis}

Statistical analyses were performed with Prism $^{\circledR} 5.02$ (GraphPad Software, San Diego, CA, USA). The correlation of EA activity units with viscoelastic $\left(\right.$ ROTEM $\left.^{\mathbb{B}}\right)$ and aggregometric (Multiplate ${ }^{\circledR}$ ) parameters were analyzed by Spearmann's correlation test. Groups were compared using the Mann-Whitney U or Kruskal-Wallis (followed by Dunn's multiple comparison) test for continuous variables and chi-square tests for categorical variables. $P<$ 0.05 was regarded as statistically significant.

\section{Results}

A total of 49 patients, all European Caucasians, fulfilled the inclusion criteria during the observation period. Characteristics are given in Table 1. Patients were 
Table 1 Characterization of patients

\begin{tabular}{|c|c|c|c|}
\hline Variables & $\begin{array}{l}\text { All } \\
n=49\end{array}$ & $\begin{array}{l}\text { SIRS } \\
n=16\end{array}$ & $\begin{array}{l}\text { Sepsis } \\
n=33\end{array}$ \\
\hline$\overline{\mathrm{Age}^{\dagger}}$ & $70(28 / 87)$ & $71.5(53 / 86)$ & $70(28 / 87)$ \\
\hline Male ${ }^{\ddagger}$ & $35(71.4)$ & $11(68.8)$ & $24(72.7)$ \\
\hline $\mathrm{BMI}^{+}$ & 27.1 (16.3 to 40.4$)$ & 27.5 (20.8 to 27.0 ) & 26.3 (16.3 to 40.4$)$ \\
\hline Infection ${ }^{\ddagger}$ & $33(67.4)$ & $0(0)$ & $33(100)$ \\
\hline \multirow[t]{4}{*}{ Infection site } & See sepsis & NA & Lung: 17 \\
\hline & & NA & Abdominal: 8 \\
\hline & & NA & Positive blood culture: 1 \\
\hline & & NA & Other: 7 \\
\hline Temperature $\left({ }^{\circ} \mathrm{C}\right)^{\dagger}$ & 36.4 (33.4 to 38.9) & 36.5 (35.2 to 38.0 ) & 36.4 (33.4 to 38.9) \\
\hline Heart rate $(\mathrm{bpm})^{\dagger}$ & 90 (60 to 140$)$ & 90 (70 to 100$)$ & $90(60$ to 140$)$ \\
\hline Respiratory rate $(\mathrm{c} / \mathrm{min})^{\dagger}$ & 15 (10 to 29$)$ & 15.5 (11 to 21$)$ & 15 (10 to 29$)$ \\
\hline Leukocytes $\left(\times 10^{9} / \mathrm{L}\right)^{\dagger}$ & $14.4(2.5$ to 48.0$)$ & 13.6 (7.1 to 28.8$)$ & $15.0(2.5$ to 48.0$)$ \\
\hline \multirow[t]{3}{*}{ Anticoagulation $^{\ddagger}$} & Heparin: 29 (59.2) & $7(43.8)$ & $22(66.7)$ \\
\hline & LMWH: 13 (26.5) & $6(37.5)$ & $7(21.2)$ \\
\hline & None: 7 (14.3) & $3(18.8)$ & $4(12.1)$ \\
\hline APACHE ॥ & 16 (5 to 29$)$ & 16 (10 to 26$)$ & $16(5$ to 29$)$ \\
\hline SAPS $\|$ & 46 (19 to 90$)$ & 43 (24 to 62$)$ & 48 (19 to 90$)$ \\
\hline
\end{tabular}

†, median (minimum-maximum); $\neq, \mathrm{n}(\%) ;$ APACHE, Acute Physiology and Chronic Health Evaluation; BMl, body mass index; bpm, beats per minute; LMWH, low molecular weight heparin; SAPS, Simplified Acute Physiology Score; SIRS, systemic inflammatory response syndrome

admitted following trauma, major surgical procedures or for postoperative complications, such as respiratory failure or resuscitation. The median (minimum-maximum) length of stay on ICU before inclusion was 2 (0 to 58) days. In 33 patients infection was present at the time of inclusion. The primary site of infection was the lung, followed by the abdomen. In one patient the blood culture was positive. Other infection sites included muscle tissue or the urinary tract (Table 1). Thrombosis prophylaxis was provided with heparin-infusion in 29 (59.2\%) or low molecular weight heparin (LMWH) in 13 (26.5\%) patients. Seven (14.3\%) patients did not receive thrombosis prophylaxis. The median (minimum-maximum) heparin-infusion rates were 400 (200 to 1,000$)$ units/h. LMWHs included enoxaparin $(\mathrm{n}=6) 70(40$ to $120) \mathrm{mg} / \mathrm{d}$, nadroparin-calcium $(\mathrm{n}=2) 5,700(3,800$ to $7,600)$ units/d and dalteparin $(\mathrm{n}=5) 10,000(10,000$ to $10,000)$ units/d. Fourteen $(28.6 \%)$ patients received antiplatelet therapy (acetylsalicylic acid, $100 \mathrm{mg} / \mathrm{d}$ ).

Patients with SIRS or sepsis did not differ significantly in age, sex, body mass index (BMI), SIRS criteria, type of anticoagulation, Acute Physiology and Chronic Health Evaluation (APACHE) II or Simplified Acute Physiology Score (SAPS) II.

\section{EA and viscoelastic ROTEM ${ }^{\circledR}$ variables}

EA levels showed a broad distribution with a median (minimum-maximum) of 0.27 (0.01 to 0.72 ). In two patients, thrombelastometric measurements failed for technical reasons. The median values (minimum-maximum) of the viscoelastic variables were CFT: $263 \mathrm{~s}$ (60 to
1,438 s), CT: $1,008 \mathrm{~s}$ (53 to $1,481 \mathrm{~s}$ ), and alpha-angle: $50^{\circ}$ $\left(17\right.$ to $\left.78^{\circ}\right)$. The primary outcome of this study, that is, the association of EA and CFT, showed a significant negative correlation $(r=-0.38, P<0.005)$ (Figure 1). Furthermore, a negative correlation was found for CT $(r=-0.29$, $P<0.05)$, a positive correlation was found for alpha-angle

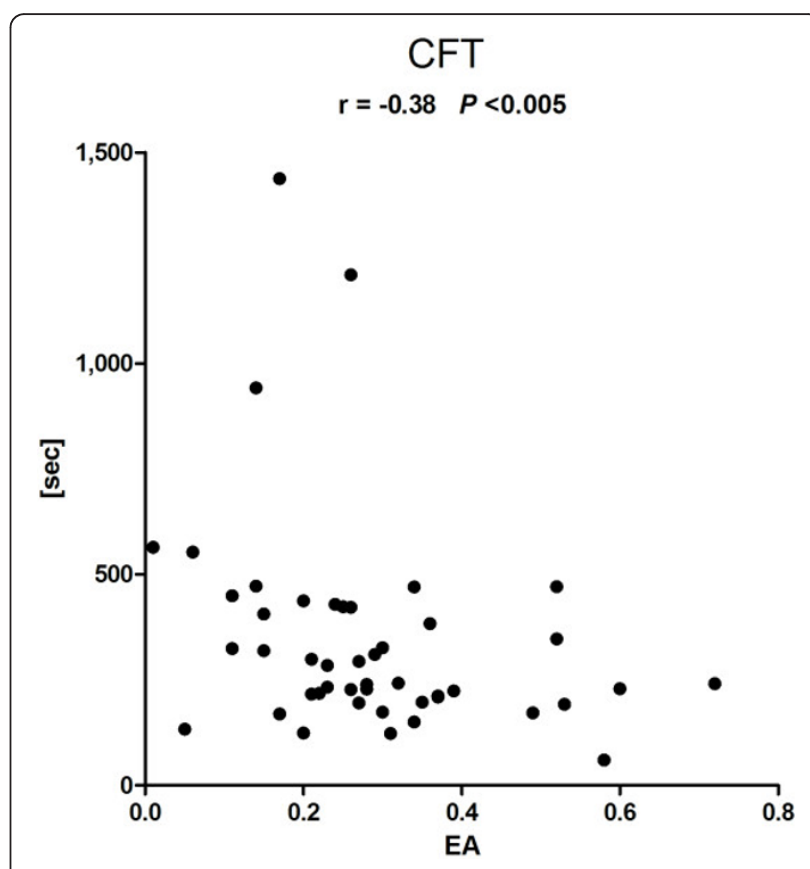

Figure 1 Endotoxin activity (EA) and NATEM clotting formation time (CFT). r, Spearman's correlation coefficient 


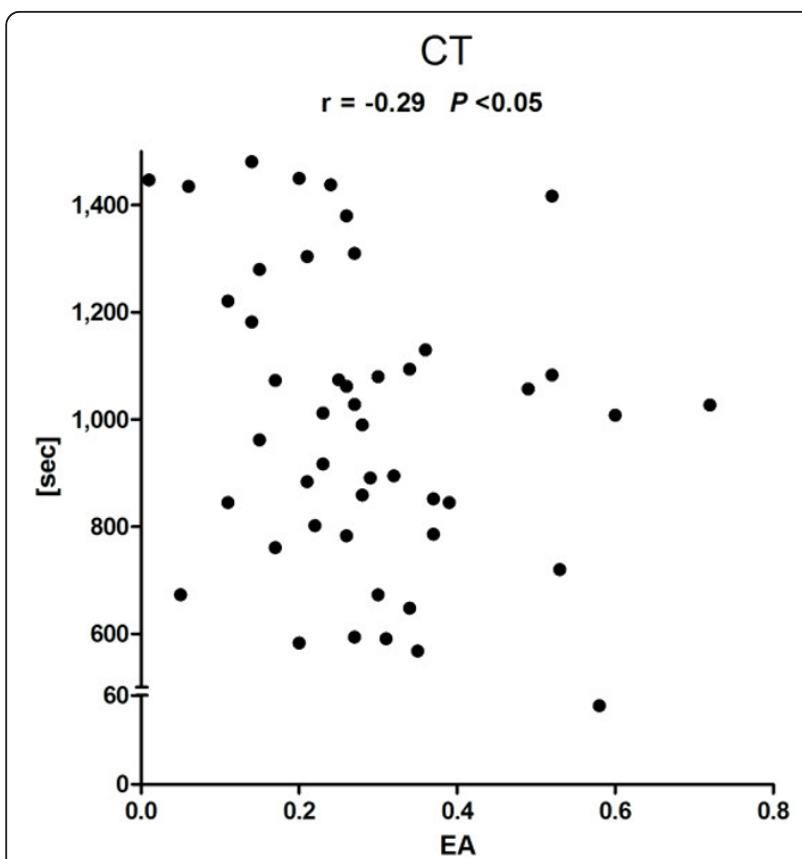

Figure 2 Endotoxin activity (EA) and NATEM clotting time (CT). $r$, Spearman's correlation coefficient

$(\mathrm{r}=0.40, P<0.005)$ (Figures 2 and 3). A positive correlation could also be observed for maximum clot firmness (MCF). No correlations were found between EA and Lysis Index at 60 minutes (LI60) (Table 2). Viscoelastic parameters did not differ significantly between patients

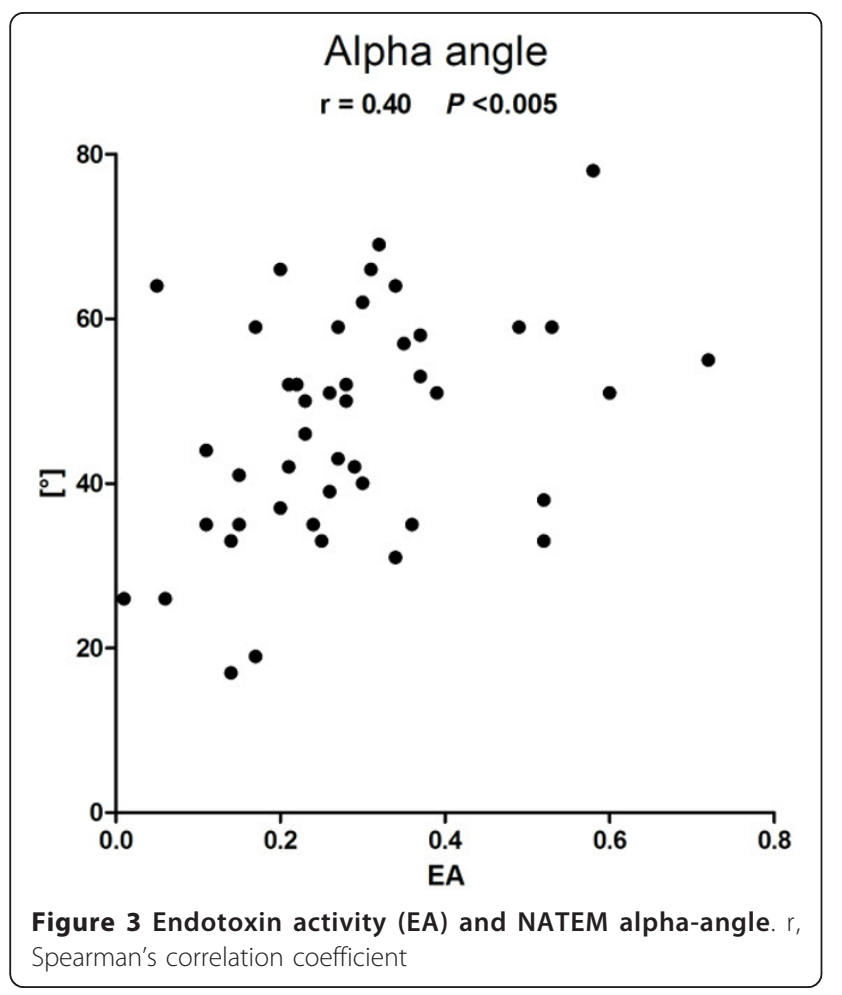

Table 2 Thrombelastometric and aggregometric findings, conventional clotting variables

\begin{tabular}{llll}
\hline Variables & Value & \multicolumn{2}{l}{ Correlation with EA } \\
\cline { 3 - 4 } & & $\mathbf{r}$ & $\boldsymbol{P}$ \\
\hline CFT (sec) & $263(60$ to 1,438$)$ & -0.38 & $<0.005$ \\
CT (sec) & $1,008(53$ to 1,481$)$ & -0.29 & $<0.05$ \\
Alpha angle ( $\left.{ }^{\circ}\right)$ & $50(17$ to 78$)$ & 0.40 & $<0.005$ \\
MCF (mm) & $55(5$ to 76$)$ & 0.27 & $<0.05$ \\
LI60 (60\%) & $98(90$ to 100$)$ & -0.04 & NS \\
ASPI (AUC (AU*min)) & $697(53$ to 1,481$)$ & 0.01 & NS \\
ADP (AUC (AU*min)) & $518(18$ to 1,176$)$ & 0.01 & NS \\
TRAP (AUC (AU*min)) & $818(122$ to 1,831$)$ & -0.05 & NS \\
Platelets ( $\times 10^{9} /$ L) & $145(17$ to 523$)$ & 0.02 & NS \\
INR & $1.39(1.04$ to 3.58$)$ & 0.01 & NS \\
APPT (sec) & $45(32$ to 112$)$ & 0.02 & NS \\
Thrombin time (sec) & $16.5(14.0$ to 95.0$)$ & -0.11 & NS \\
Fibrinogen (mg/dL) & $440(60$ to 1,106$)$ & -0.10 & NS \\
Antithrombin (\%) & $62(27$ to 90$)$ & -0.08 & NS
\end{tabular}

ADP, adenosine diphosphate activated aggregometric analysis; aPPT, activated partial thromboplastin time; median (minimum-maximum); ASPI, arachidonic acid activated aggregometric analysis; CFT, clotting formation time; CT, clotting time; INR, international normalized ratio; LI60, 60-minute lyses index MCF, maximum clot firmness; TRAP, thrombin receptor activating peptide 6 activated aggregometric analysis

receiving heparin-infusion, LMWH or no antithrombosis prophylaxis (data not shown).

\section{EA and aggregometric Multiplate ${ }^{\circledR}$ variables}

No significant relations were found between EA and ASPItest, ADP-test or TRAP-test (Table 2). Aggregometric parameters and correlations to EA were not influenced significantly by antiplatelet therapy (data not shown).

\section{EA and conventional clotting variables}

No significant correlations were found between EA and platelet count, International Normalized Ratio (INR), activated Partial Thromboplastin Time (aPPT), fibrinogen concentration, thrombin time or antithrombin activity (Table 2).

\section{SIRS versus sepsis}

EA activity, thrombelastometric, aggregometric or conventional clotting parameters did not differ significantly between SIRS and sepsis patients (Table 3).

\section{Discussion}

In this prospective observational study we investigated the relation between systemic endotoxin levels and clotting dynamics. We found EA levels to negatively correlate with CFT and CT. Positive correlations were found for alpha-angle and MCF, indicating that clot formation was faster and firmer when EA levels were higher. We did not observe any effect of EA levels on LI60, that is, clot lyses. Furthermore, there was no correlation 
Table 3 EA, thrombelastometric and aggregometric findings, conventional clotting variables in SIRS and sepsis patients

\begin{tabular}{llll}
\hline & SIRS & Sepsis & \\
\hline Variables & Value & Value & $\boldsymbol{P}$ \\
\hline EA & $0.27(0.14$ to 0.52$)$ & $0.27(0.01 / 0.72)$ & NS \\
CFT (sec) & $263(150$ to 1,438$)$ & $268(60 / 942)$ & NS \\
CT (sec) & $906(648$ to 1,380$)$ & $1027(53$ to 1,481$)$ & NS \\
Alpha-angle ( $\left.{ }^{\circ}\right)$ & $50(24$ to 69$)$ & $47(17$ to 78$)$ & NS \\
MCF (mm) & $53(24$ to 67$)$ & $57(5$ to 76$)$ & NS \\
LI60 (60\%) & $98(90$ to 100$)$ & $99(93$ to 100$)$ & NS \\
ASPI (AUC (AU*min)) & $506(49$ to 1,137$)$ & $772(21$ to 1,667$)$ & NS \\
ADP (AUC (AU*min)) & $539(125$ to 804$)$ & $504(18$ to 1,176$)$ & NS \\
TRAP (AUC (AU*min)) & $799(339$ to 1,494$)$ & $887(122$ to 1,831$)$ & NS \\
Platelets $\left(\times 10^{9} /\right.$ L) $)$ & $131(61$ to 257$)$ & $166(17$ to 523$)$ & NS \\
INR & $1.40(1.14$ to 3.58$)$ & $1.37(1.04$ to 2.12$)$ & NS \\
APPT (sec) & $44(38$ to 112$)$ & $45(32$ to 79$)$ & NS \\
Thrombin time (sec) & $17(14$ to 95$)$ & $16(14$ to 79$)$ & NS \\
Fibrinogen (mg/dL) & $392(60$ to 829$)$ & $451(112$ to 1,106$)$ & NS \\
Antithrombin (\%) & $57(31$ to 90$)$ & $62(27$ to 88$)$ & NS \\
\hline ADP, adenosne diphosphat
\end{tabular}

ADP, adenosine diphosphate activated aggregometric analysis; aPPT, activated partial thromboplastin time; median (min-max); ASPI, arachidonic acid activated aggregometric analysis; CFT, clotting formation time; CT, clotting time; EA, endotoxin activity; INR, international normalized ratio; LI60, 60minute lyses index; MCF, maximum clot firmness; TRAP, thrombin receptor activating peptide 6 activated aggregometric analysis

between EA levels and platelet function, as investigated by aggregometric measurements (ASPI-, ADP-, TRAPtest). Also, conventional clotting tests (platelet count, INR, aPPT, thrombin time) or clotting factor measurements (fibrinogen, antithrombin) did not correlate with EA levels. There were no differences in EA levels, thrombelastometric, aggregometric or conventional clotting parameters between SIRS and sepsis patients.

SIRS following major surgery (for example, heart surgery, liver transplantations), burns or major trauma is associated with increased endotoxin blood levels [17-24]. It is thought that endotoxin translocates in the context of gastrointestinal hypoperfusion and gut failure. Thereby, EA in the blood seems to mainly reflect organ dysfunction with regard to the integrity of the gut, which can be observed in patients with SIRS, Gram positive or Gram negative sepsis $[25,26]$. In patients with systemic inflammation caused by infection, that is, sepsis, EA levels tend to be higher. However, we and others showed that EA levels do not discriminate between SIRS and sepsis [4]. With the intention of measuring a broad range of EA levels, we defined the presence of two SIRS criteria as inclusion criteria, regardless of cause or severity of systemic inflammation. EA levels can be graduated into low $(<0.4)$, intermediate $(0.40$ to 0.59$)$ and high $(\geq 0.6)$. The range of EA levels we observed are slightly lower, however, of a comparable broad spread when compared to the MEDIC study
[4]. This allowed us to correlate various EA levels with corresponding thrombelastographic and aggregometric parameters. The fact that we observed lower EA levels compared to the MEDIC study could be due to differences in inclusion times. While all patients of the MEDIC study were included within $24 \mathrm{~h}$, the median inclusion time in our study was $2 \mathrm{~d}$ after ICU admission. One could speculate that in our population initial stabilisation following, for example, surgery was more advanced, and surgery related endotoxin release was of reduced impact.

In 33 patients, SIRS was associated with infection, resulting in sepsis, severe sepsis or septic shock. Our analysis did not discriminate between the different grades of sepsis, as this would result in small group numbers. Furthermore, we aimed to investigate the mere effect of EA on thrombelastographic and aggregometric parameters, rather than trying to detect differences between groups to which patient allocation often is difficult.

TLR activation results in the intracellular activation of $\mathrm{NF}-\kappa \mathrm{B}$ and the subsequent release of various cytokines, nitric oxide, several other mediators and tissue factor (TF) $[5,27]$. Circulating TF is released primarily by activated monocytes, granulocytes and macrophages. Various conditions, including SIRS and sepsis, are related to increased TF levels $[28,29]$. The central role of TF in systemic inflammation could be demonstrated by blocking TF in Escherichia coli-induced septic shock, which increased survival in an animal model [30]. In human volunteers, the injection of LPS leads to a fast increase of TF mRNA in monocytes [31]. TF activates the TF/ FVIIa pathway, activating FIX and FX, resulting in thrombin formation [32]. On the other hand, anticoagulatory mediators like antithrombin, protein $\mathrm{C}$ and $\mathrm{S}$ levels are decreased during systemic inflammation, supporting the procoagulatory state of the clotting system $[33,34]$.

In in vitro and animal experiments as well as in healthy subjects, clotting activation by endotoxin could be observed $[7,35,36]$. In healthy volunteers, low dose endotoxin, compared to placebo, reduces CT, but does not affect CFT or MCF [8]. Thrombelastometric observations performed with NATEM-tests in patients with severe sepsis demonstrate that compared to healthy controls, MCF and alpha-angle were increased, that is, clot formation was firmer [37]. Also performing the NATEM-test, Adamzik et al. observed a shorter CT and CFT, and a higher alpha-angle in septic patients compared to healthy probands [9]. As severe sepsis is associated with high EA levels, these results would be in line with our findings. However, some further, earlier studies with ROTEM $^{\mathbb{B}}$ in patients with severe sepsis or septic shock are difficult to interpret and probably not 
comparable with our findings [12,38]. This is because clotting activators were used (INTEM, EXTEM and so on). ROTEM ${ }^{\circledR}$ analysis working with clotting activators, such as the INTEM- or the EXTEM-test, might not be sensitive enough to detect clotting abnormalities caused by systemic inflammation/infection. For example, the EXTEM-test uses TF as an activator. As TF is thought to be a central player during inflammatory induced clotting, using it as an activator might override the effects we aimed to investigate. In our study, we omitted activators by using the NATEM-test with heparinase only. Furthermore, the inclusion time in previous trials often was not focused on early systemic inflammation, but on established sepsis. With the inclusion criteria severe sepsis or septic shock, the inclusion time tends to be later compared with the inclusion criteria SIRS, as microbiology results often are essential for the diagnosis severe sepsis and septic shock.

Recently, it was demonstrated that impedance aggregometry has diagnostic and prognostic value in patients with severe sepsis. Compared to post-surgical patients, patients with severe sepsis showed reduced platelet aggregation in the collagen-test, ADP-test, AAtest and TRAP-test [14]. Our results did not show differences in aggregometric variables between SIRS and sepsis patients. This might be explained by the fact that in SIRS patients, systemic inflammation can be more severe than in post-surgical patients. Furthermore, the sepsis group in our study also included patients with sepsis without organ dysfunction, that is, a less severe form of sepsis compared to severe sepsis. Therefore, in our patient groups (SIRS vs. sepsis) clinically and inflammatory conditions were more contiguous, which might explain the absence of differences in our results. Another study, comparing post-surgical with septic shock patients did not, with the exception of ADP, find differences in aggregometric variables (ASPI, COL, TRAP-test) [12]. Again, investigated patient groups (post-surgical vs. septic shock) differed from ours.

The absence of a correlation between EA levels and conventional clotting parameters, as well as the fact that the groups SIRS and sepsis did not differ in this regard, is in line with previous observations. In septic patients, platelet counts tend to be lower when compared to healthy individuals, but not compared to post surgical or SIRS patients [12,39]. Perioperative systemic endotoxin concentrations do not correlate with platelet counts or aPPT $[40,41]$. Prothrombin time (PT) (in our study represented by INR) does not differ between controls, patients with sepsis or severe sepsis. Only in patients with septic shock, a prolongation can be observed [42]. Therefore, our results support the insight that global clotting tests are not sensitive enough to detect clotting derangements caused by systemic inflammation, apart from extremes, such as septic shock.

This study focused on early SIRS and sepsis states. With the progress of SIRS or sepsis, EA level and coagulation courses over time become extremely complex by the influence of various unbalanced pro- and antiinflammatory/pro- and anti-coagulatory mechanisms. This is in line with our observations, which initially included analysis for five consecutive days. With EA levels and coagulatory variables following indefinable courses, we focused on early stages of SIRS and sepsis. Still, the correlations we found are not very intense. This might reflect the above mentioned fast and diverse dynamic of inflammatory and coagulatory processes, whose exact onset cannot precisely be captured by a screening resolution of 24 hours. Potentially, higher numbers of patients would have adjusted this synchronisation deficiency. Furthermore, medical histories and clinical conditions of the patients were very heterogeneous, which should be considered when interpreting the levels of correlation coefficients.

\section{Conclusion}

The impact of endogenously released endotoxin on clotting has not been evaluated before. Here we demonstrate a correlation between EA levels and viscoelastic parameters, suggesting an in vivo link between endogenous endotoxin concentrations and coagulation. With increasing EA levels clot formation becomes faster and firmer in patients with early systemic inflammation, independent of cause (non-infectious or infectious) or severity. With the development of endotoxin neutralizing therapeutic options, the further understanding of the link between systemic inflammation and coagulation might be of relevance [25].

\section{Key messages}

- In patients with early systemic inflammation, increasing endotoxin concentration correlates with faster and firmer clot formation.

- Neither platelet counts or function nor conventional clotting parameters were influenced by endotoxin concentration.

- Patients with SIRS did not differ from patients with sepsis in endotoxin concentrations, clot formation, platelet counts or function, or conventional clotting parameters.

\section{Abbreviations}

ADP, adenosine diphosphate activated aggregometric analysis; APACHE, Acute Physiology and Chronic Health Evaluation; aPPT, activated partial thromboplastin time; ASPI, Arachidonic Acid Activated Aggregometric Analysis; BMI, body mass index; bpm, beats per minute; CFT, clot formation time; CT, clotting time; EA, endotoxin activity; EAA, Endotoxin Activity Assay; EDTA, ethylenediaminetetraacetic acid; INR, international normalized ratio; 
LI60, 60-minute lyses index; LMWH, low molecular weight heparin; LPS, lipopolysaccharide; MCF, maximum clot firmness; PRRs, pattern recognition receptors; PT, prothrombin time; SAPS, simplified acute physiology score: SIRS, systemic inflammatory response syndrome; TF, tissue factor; TEM, thrombelastometry; TLR, toll-like receptor; TRAP, thrombin receptor activating peptide 6 activated aggregometric analysis

\section{Competing interests}

The authors declare that they have no competing interests.

\section{Authors' contributions}

AK designed the study, screened and enrolled patients, analyzed and interpreted the data, and wrote the manuscript. MIM screened patients, performed the bedside measurements, collected patient data, analyzed and interpreted the data, and revised the manuscript for important intellectual content. BS assisted in processing and analyzing the data, and revised the manuscript for important intellectual content. CB obtained funding and revised the manuscript for important intellectual content. KZ conceived of the study, obtained funding, participated in its design and coordination, headed the project, and revised the manuscript for important intellectual content. All authors read and approved the final manuscript.

\section{Acknowledgements}

Reagents for the Endotoxin Activity Assay were kindly provided by Spectral Diagnostics Inc., Toronto, ON, Canada, which had no influence on the trial protocol or conduct or data analyses or reporting.

\section{Authors' details}

${ }^{1}$ Clinic of Anesthesiology, Intensive Care Medicine and Pain Therapy, University Hospital Frankfurt, Theodor-Stern-Kai 7, Frankfurt am Main 60590, Germany. ${ }^{2}$ Department of Anesthesiology, VU University Medical Center, De Boelelaan 1117, 1081 HV Amsterdam, The Netherlands.

Received: 12 April 2013 Revised: 6 June 2013

Accepted: 11 September 2013 Published: 11 September 2013

\section{References}

1. Puleo F, Arvanitakis M, Van Gossum A, Preiser JC: Gut failure in the ICU. Semin Respir Crit Care Med 2011, 32:626-638.

2. Nakamura M, Shimizu Y, Sato Y, Miyazaki Y, Satoh T, Mizuno M, Kato Y, Hosaka Y, Furusako S: Toll-like receptor 4 signal transduction inhibitor, M62812, suppresses endothelial cell and leukocyte activation and prevents lethal septic shock in mice. Eur J Pharmacol 2007, 569:237-243.

3. Chong DL, Sriskandan S: Pro-inflammatory mechanisms in sepsis. Contrib Microbiol 2011, 17:86-107.

4. Marshall JC, Foster D, Vincent JL, Cook DJ, Cohen J, Dellinger RP, Opal S, Abraham E, Brett SJ, Smith T, Mehta S, Derzko A, Romaschin A, MEDIC study: Diagnostic and prognostic implications of endotoxemia in critical illness: results of the MEDIC study. J Infect Dis 2004, 190:527-534.

5. Levi M, van der Poll T: Inflammation and coagulation. Crit Care Med 2010, 38(2 Suppl):S26-S34

6. Esmon $\mathrm{CT}$ : The interactions between inflammation and coagulation. $\mathrm{Br} \mathrm{J}$ Haematol 2005, 131:417-430.

7. Zacharowski K, Sucker C, Zacharowski P, Hartmann M: Thrombelastography for the monitoring of lipopolysaccharide induced activation of coagulation. Thromb Haemost 2006, 95:557-561.

8. Spiel AO, Mayr FB, Firbas C, Quehenberger P, Jilma B: Validation of rotation thrombelastography in a model of systemic activation of fibrinolysis and coagulation in humans. J Thromb Haemost 2006, 4:411-416.

9. Adamzik M, Eggmann M, Frey UH, Gorlinger K, Brocker-Preuss M, Marggraf G, Saner F, Eggebrecht H, Peters J, Hartmann M: Comparison of thromboelastometry with procalcitonin, interleukin 6, and C-reactive protein as diagnostic tests for severe sepsis in critically ill adults. Crit Care 2010, 14:R178.

10. Adamzik M, Langemeier T, Frey UH, Gorlinger K, Saner F, Eggebrecht $H$, Peters J, Hartmann M: Comparison of thrombelastometry with simplified acute physiology score II and sequential organ failure assessment scores for the prediction of 30-day survival: a cohort study. Shock 2011, 35:339-342.

11. Fitzgerald JR, Foster TJ, Cox D: The interaction of bacterial pathogens with platelets. Nat Rev Microbiol 2006, 4:445-457.
12. Brenner T, Schmidt K, Delang M, Mehrabi A, Bruckner T, Lichtenstern C, Martin E, Weigand MA, Hofer S: Viscoelastic and aggregometric point-ofcare testing in patients with septic shock - cross-links between inflammation and haemostasis. Acta Anaesthesiol Scand 2012, 56:1277.

13. Johansson D, Shannon O, Rasmussen M: Platelet and neutrophil responses to Gram positive pathogens in patients with bacteremic infection. PLOS One 2011, 6:e26928.

14. Adamzik M, Gorlinger K, Peters J, Hartmann M: Whole blood impedance aggregometry as a biomarker for the diagnosis and prognosis of severe sepsis. Crit Care 2012, 16:R204.

15. Hanke AA, Roberg K, Monaca E, Sellmann T, Weber CF, Rahe-Meyer N, Gorlinger K: Impact of platelet count on results obtained from multiple electrode platelet aggregometry (Multiplate). Eur J Med Res 2010, 15:214-219.

16. Bone RC, Balk RA, Cerra FB, Dellinger RP, Fein AM, Knaus WA, Schein RM, Sibbald WJ: Definitions for sepsis and organ failure and guidelines for the use of innovative therapies in sepsis. The ACCP/SCCM Consensus Conference Committee. American College of Chest Physicians/Society of Critical Care Medicine. Chest 1992, 101:1644-1655.

17. Sanada Y, Mizuta K, Urahashi T, Ihara Y, Wakiya T, Okada N, Yamada N, Ushijima K, Otomo S, Sakamoto K, Yasuda Y, Kawarasaki H: Impact of endotoxin measured by an endotoxin activity assay during liver transplantation. J Surg Res 2012, 180:349.

18. Kats S, Schönberger JP, Brands R, Seinen W, van Oeveren W: Endotoxin release in cardiac surgery with cardiopulmonary bypass: pathophysiology and possible therapeutic strategies. An update. Eur J Cardiothorac Surg 2011, 39:451-458

19. Pfeiffer L, Ehrhardt N, Kretzschmar M, Urbaschek R, Schubert K, Schirrmeister W: [Endotoxinemia and multiple organ failure after polytrauma]. Anaesthesiol Reanim 1996, 21:91-96.

20. Maejima K, Deitch E, Berg R: Promotion by burn stress of the translocation of bacteria from the gastrointestinal tracts of mice. Arch Surg 1984, 119:166-172.

21. Deitch EA, Ma WJ, Ma L, Berg R, Specian RD: Endotoxin-induced bacterial translocation: a study of mechanisms. Surgery 1989, 106:292-299.

22. Wiest R, Rath HC: Gastrointestinal disorders of the critically ill. Bacterial translocation in the gut. Best Pract Res Clin Gastroenterol 2003, 17:397-425.

23. Qiao Z, Li Z, Li J, Lu L, Lv Y: Bacterial translocation and change in intestinal permeability in patients after abdominal surgery. J Huazhong Univ Sci Technolog Med Sci 2009, 29:486-491.

24. Valenza F, Fagnani L, Coppola S, Froio S, Sacconi F, Tedesco C, Maffioletti M, Pizzocri M, Salice V, Ranzi ML, Marenghi C, Gattinoni L: Prevalence of endotoxemia after surgery and its association with ICU length of stay. Crit Care 2009, 13:R102.

25. Monti G, Bottiroli M, Pizzilli G, Minnini M, Terzi V, Vecchi I, Gesu G, Brioschi P, Vesconi S, Casella G: Endotoxin activity level and septic shock: a possible role for specific anti-endotoxin therapy? Contrib Nephrol 2010, 167:102-110

26. Romaschin AD, Klein DJ, Marshall JC: Bench-to-bedside review: clinical experience with the endotoxin activity assay. Crit Care 2012, 16:248.

27. Pawlinski R, Pedersen B, Schabbauer G, Tencati M, Holscher T, Boisvert W, Andrade-Gordon P, Frank RD, Mackman N: Role of tissue factor and protease-activated receptors in a mouse model of endotoxemia. Blood 2004, 103:1342-1347.

28. Levi M, van der Poll T, ten Cate H: Tissue factor in infection and severe inflammation. Semin Thromb Hemost 2006, 32:33-39.

29. Key NS, Mackman N: Tissue factor and its measurement in whole blood, plasma, and microparticles. Semin Thromb Hemost 2010, 36:865-875.

30. Taylor FB Jr, Chang A, Ruf W, Morrissey JH, Hinshaw L, Catlett R, Blick K, Edgington TS: Lethal E. coli septic shock is prevented by blocking tissue factor with monoclonal antibody. Circ Shock 1991, 33:127-134.

31. Franco RF, de Jonge E, Dekkers PE, Timmerman JJ, Spek CA, van Deventer SJ, van Deursen P, van Kerkhoff L, van Gemen B, ten Cate H, van der Poll T, Reitsma PH: The in vivo kinetics of tissue factor messenger RNA expression during human endotoxemia: relationship with activation of coagulation. Blood 2000, 96:554-559.

32. Egorina EM, Sovershaev MA, Hansen JB: The role of tissue factor in systemic inflammatory response syndrome. Blood Coagul Fibrinolysis 2011, 22:451-456.

33. Levi M: The coagulant response in sepsis. Clin Chest Med 2008, 29:627-642, viii. 
34. Semeraro N, Ammollo CT, Semeraro F, Colucci M: Sepsis, thrombosis and organ dysfunction. Thromb Res 2012, 129:290-295.

35. Morrison DC, Cochrane CG: Direct evidence for Hageman factor (factor XII) activation by bacterial lipopolysaccharides (endotoxins). J Exp Med 1974, 140:797-811.

36. McKay KD, Shapiro SS: Alterations in the blood coagulation system induced by bacterial endotoxin. I. In vivo (generalized Shwartzman reaction). J Exp Med 1958, 107:353-367.

37. Collins PW, Macchiavello LI, Lewis SJ, Macartney NJ, Saayman AG, Luddington R, Baglin T, Findlay GP: Global tests of haemostasis in critically ill patients with severe sepsis syndrome compared to controls. Br J Haematol 2006, 135:220-227.

38. Daudel F, Kessler U, Folly H, Lienert JS, Takala J, Jakob SM:

Thromboelastometry for the assessment of coagulation abnormalities in early and established adult sepsis: a prospective cohort study. Crit Care 2009, 13:R42.

39. Brunkhorst FM, Wegscheider K, Forycki ZF, Brunkhorst R: Procalcitonin for early diagnosis and differentiation of SIRS, sepsis, severe sepsis, and septic shock. Intensive Care Med 2000, 26(Suppl 2):S148-152.

40. Kokuba Y, Nakao A, Takagi H: Changes in the blood endotoxin concentration after digestive surgery. Surg Today 1993, 23:100-104.

41. Li J, Liu Y, Yin W, Zhang C, Huang J, Liao C, Nie L, Zhou Y, Xiao P: Alterations of the preoperative coagulation profile in patients with acute appendicitis. Clin Chem Lab Med 2011, 49:1333-1339.

42. Mavrommatis AC, Theodoridis T, Orfanidou A, Roussos C, ChristopoulouKokkinou V, Zakynthinos S: Coagulation system and platelets are fully activated in uncomplicated sepsis. Crit Care Med 2000, 28:451-457.

doi:10.1186/cc12892

Cite this article as: Koch et al: Systemic endotoxin activity correlates with clot formation: an observational study in patients with early systemic inflammation and sepsis. Critical Care 2013 17:R198.

\section{Submit your next manuscript to BioMed Central} and take full advantage of:

- Convenient online submission

- Thorough peer review

- No space constraints or color figure charges

- Immediate publication on acceptance

- Inclusion in PubMed, CAS, Scopus and Google Scholar

- Research which is freely available for redistribution

Submit your manuscript at www.biomedcentral.com/submit 